\title{
Critical Thinking and Chinese International Students: An East-West Dialogue
}

\author{
Michael O'Sullivan \\ Brock University \\ mosullivan@brocku.ca \\ Linyuan Guo \\ University of Prince Edward Island \\ liguo@upei.ca
}

\begin{abstract}
In the West, the teaching of critical thinking, albeit differentially defined, is seen as the core of work at a graduate level. Despite the fact that developing such critical skills is increasing as an expectation of schools in the West, the literature reflects concerns that Canadian educated students arrive at university unprepared to engage at the expected level of criticality. If this is true of domestic students, what is the situation facing those international students who were educated in intellectual traditions, such as China's, where critical thinking, at least as understood in the West, is rarely encouraged, and often actually discouraged? Do such students arrive prepared to work at a postsecondary level that involves critical thinking? Do such students embrace or resist critical thinking when these skills are taught to them? Is teaching critical thinking to these students a legitimate scholarly pursuit or is it, in effect, a neocolonial conceit? Can the Asian notion of harmony be reconciled with the Western notion of often-times sharp engagement with ideas and debate with their classmates and instructors? The authors, one a Canadian born and raised professor of comparative and international education to Chinese students studying in Canada, the other, a Chinese scholar who recently completed her doctorate in Canada where she now teaches, engage in a dialogue on Western concepts of critical thinking and the reaction of one class of Chinese international students to this pedagogy.
\end{abstract}

\section{Introduction}

From virtually the first day of their intensive 14-month Master of Education program at Brock University, the Chinese students of the Faculty of Education's International Student Program (ISP) are introduced to, and encouraged to apply, the concept of critical thinking. This paper constitutes a reflection upon O'Sullivan's experience of teaching critical thinking to the Chinese students in the ISP. The journey that I have taken in this process of reflection has increased my conviction that those of us who teach critical thinking to any group of students, domestic or international, need to be constantly aware of, and attentive to, our assumptions about what we mean by critical thinking and how we engage pedagogically when we teach critical thinking.

Journal of Contemporary Issues in Education, 2010, 5(2), pp.53- 73

ISSN 1718-4770 @ 2010 University of Alberta

http://ojs.educ.ualberta.ca/index.php/jcie/ 
Your teaching reflection reminds me of the confusion I experienced during the first couple years of my learning experience when I started my graduate study at the University of Alberta several years ago. Critical thinking was never formally introduced during classes; however, my professor's comments on my writing assignments frequently made reference to my lack of criticality. It was not uncommon for me to receive comments like "you should discuss more critically ...". There is an assumption by professors who teach graduate courses that the concept and practice of critical thinking has been mastered by their students, including international students, and all graduate students should have developed good critical thinking skills as a result of their previous education. This phenomenon was particularly challenging for me as an international student from China because the concept of critical thinking, developed in the Eurowestern world, is absent from Chinese education discourse at both secondary and postsecondary levels. I am very pleased that you recognized, and did not ignore, this issue. In the Canadian education context in which critical thinking is valued philosophically and pedagogically, your reflection on teaching critical thinking to international students from different learning environments and educational systems is very meaningful. I believe all students, and instructors who teach international students with diverse cultural and educational backgrounds, should give special consideration to this topic as it provides opportunities for all of us to critique our educational views and underlying philosophies from new perspectives.

\section{What Critical Thinking Do We Teach?}

The emergence of the dominant form of critical thinking (dominant in the sense of being widely practiced and formally authorized) can be linked to the publication in the United States in 1983 of A Nation at Risk. This report was written in response to government fears that the American educational system was not producing the quality of mind required to maintain US superiority in the face of foreign competition. It favoured improving student "reasoning skills" across the curriculum (Walters, 1994, p. 3). The enthusiasm with which this initiative was undertaken was described as a critical thinking explosion on US campuses with the emergence of a first wave of positivist critical thinkers (Walters, p. 4).

The net result of this undoubtedly well-intentioned effort to enhance students' thinking skills resulted in a pedagogy that Giroux (1994) calls the "internal consistency position" (p. 200). For the advocates of this approach

... critical thinking refers primarily to teaching students how to analyze and develop reading and writing assignments from the perspective of formal, logical patterns of consistency. In this case, the student is taught to examine the logical development of a theme, "advance organizers," systematic argument, the validity of evidence, and how to determine whether a conclusion flows from the data under study. While all of the latter learning skills are important, their limitations as a whole [in this approach] lie in what is excluded, and it is with respect to what is missing that the ideology of such an approach is revealed. (pp. 200-201)

Teaching about logic analysis and consistency in reading and writing is actually an important part of pre-university education in China, particularly in mathematics, 
language arts, science, and politics. This type of teaching is not explicitly called critical thinking as it is in the Western context. However, I believe if you ask your students if and how they learned these specific skills, they might well give you classroom examples, but they wouldn't refer to it as critical thinking. The Chinese terms used to describe these understandings of critical thinking are luo ji (logic), tu li (deduction), yan yi (induction), and lian guan (consistency). In my experience, Chinese and Canadians have different understandings and practices of consistency in writing, because of the unique linguistic features of the two languages. Good writing in Chinese is not the same as good writing in English, and this constitutes a challenge for your students who just started academic writing in English.

In the face of this mainstreaming (Ibrahim, 2005) of critical thinking, Walters (1994) identified the emergence of a second wave of critical thinking. For second wave advocates, critical thinking constitutes a way of creating an intellectual framework which frees the student "from dominance by ... the frames of reference [and] the worldviews in which one becomes critically literate" (Paul, 1994, p. 182).

In order to critique and become free from the dominant worldview in which they become critically literate, do students need to understand the other worldviews first? If yes, have your students had opportunities to learn about other worldviews or frames of references before critiquing their own worldviews?

The first wave approach to critical thinking does not question the hegemonic intellectual "frames of reference and worldviews" in which the student becomes literate. It has the more restrictive purpose of developing rigorous rational thought regarding problem solving within the logical framework of the dominant social structure and the worldview which gives it its legitimacy. The second wave of critical thinking seeks to explore more fundamental questions about the characteristics of the dominant social structure and the hegemonic ideology which provides it with intellectual coherence.

For Canadian students, the dominant social structure is economically capitalist (and, at least until the recent global financial meltdown, increasingly neoliberal) and politically liberal-democratic. For Chinese students, their reality is economically capitalist (or "market socialist") and neoliberal, while politically it is authoritarian. These are the "systems" within which Canadians and Chinese, respectively, learn to think, and which they have to critically examine in order to develop their own autonomous thinking about these systems and their received truths. Paul (1994) refers to this as achieving "critical empowerment" (p. 182).

I agree with your description of the economic and political contexts in Canada and China. Social and educational contexts/systems are also worthy of note in this case. Canadian society favors the individual perspective and independent thinking, while Chinese culture favors a holistic perspective and the collective good which places a great emphasis on harmony and "not losing face" (bu diu mian zi). Disagreeing with someone's opinion in public is consciously or unconsciously avoided. Canadian education is learner-centered and students take active roles and responsibilities in the 
learning process. Education in China is still very much teacher-centered and examoriented and students are expected to follow teachers' instruction and thinking in order to achieve good marks in exams. Although this is gradually changing because of dramatic nation-wide curriculum reform, the traditional education paradigm will not change quickly. The authoritarian political and learning contexts in China themselves resist the development of student autonomous thinking.

Paul (1994) notes that what he calls "critical empowerment" will not "be achieved overnight in one course" (p. 182). Students come to class more or less fully formed in one of the several variants of the positivist tradition and "if students are to learn to think critically in a strong sense, they must be exposed to [such a critical approach to pedagogy] over an extended period of time, over years, not months" (p. 182). Clearly, this has implications for teaching any students; however, it is particularly troublesome when teaching Chinese students in the ISP.

First of all, they are with us only 14 months after spending at least 16 years in Chinese educational institutions where the primary orientation for the first 12 of those years is to score among the top $10 \%$ in the National College Entrance Exams (NCEE) in order to insure a place in the more prestigious post secondary institutions in China. Preparation for these exams, which begins at the earliest stage of the formal academic experience, deeply entrenches the skill of rote memorization, while actively discouraging the development of the habits of mind required to call into question fundamental assumptions, be they social, political, or cultural.

Secondly, we must take into consideration the resistance of Chinese students to having China referred to in terms that they perceive as negative. This is especially true when comments are made that challenge values, institutions, customs, and practices which they have come to accept or revere. In contrast, while their Canadian-born peers will undoubtedly be intellectually challenged by critical thinking, the arguments presented will have an air of familiarity, and it is unlikely that they will feel what is being said is coming from a possibly hostile national perspective that is not their own. Whereas, in the case of the Chinese students, when the object of critical inquiry is China, especially when the instructor, as invariably will be the case, is not Chinese, this element is introduced and leads to the noted sensitivity to criticisms of China from foreigners.

Being challenged about one's own system, opinion, and values in public is viewed as "losing face" (diu mian zi) and is considered disgraceful in the Confucian tradition. Critical thinking is often translated as "pi pan shi si wei", which literally means looking for faults in others. It is easy to understand how students who have not been taught this [critical] pedagogy and who, furthermore, come from a very different philosophical tradition, could easily conclude that critical thinking is negative thinking. I think this is reflected in your interviews: student responses-indicated their perception that the course objective was to guide them to look for the negative aspects of the Chinese system, which is very different from your actual objective of teaching critical thinking.

In addition to the misleading Chinese translation and ambiguous meaning of critical thinking, I believe the international political context at the time of your teaching should not be ignored as it may be one reason for students' resistance to learning critical 
thinking through topics about China. As the largest developing country, China occupies, and will increasingly occupy, a position of major global economic and political power. During the time of your teaching the course analyzed in this article (January to March, 2008), there were reports of resentment and resistance from Chinese International students overseas to Western media reports on Chinese human right issues, especially with respect to Tibet. The topics you covered in class in fact reflected the many issues referred to in North American media. This would help explain why Chinese students were sensitive about the topics covered in the class.

Finally, both waves of critical thinking are, for international Chinese students, mediated through a cultural lens that undoubtedly shifts its meaning in ways that nonChinese educators may have trouble anticipating.

What you refer to as first wave critical thinking is, in fact, being taught in China, but not the so-called second wave, or critical pedagogy approach to critical thinking. The Chinese curriculum does not include an approach that, as you put it, "challenges [the] values, institutions, customs, and practices" of the dominant society, in this case, China.

\section{The International Student Program (ISP): Context}

The (xxxx university of the first author) actively recruits students from China for its International Student Program (ISP), and typically accepts from 15 to 20 recent graduates of Chinese undergraduate institutions. The program allows them to complete an M. Ed. over a short, but intense, period. The ISP is a cohort program which means, except in occasional individual cases, the members of the group take all their classes together and no student who is not -part of the cohort can join the group for a given class. It is very much a self-contained program, a practice which arose primarily from the students' difficulties with following lectures in English and the need to adjust the pace of instruction accordingly.

The ISP students begin their program in July each year with two courses that introduce them to the expectations associated with graduate study at a Canadian university, including an introduction to research methodology, essay writing skills, and the APA style manual. The importance of critical thinking is infused throughout all the courses. Upon completion of their courses the following April, the students write an exit project which must be completed by late August in order for them to graduate in the Fall. You might consider giving this cohort of students the opportunity to participate in discussions with non-Chinese students in a regular class. This would enable them to observe how students from Canada, and/or other countries, demonstrate critical thinking skills and perspectives in class. In my opinion, having all the Chinese students in one class isolates them from the benefit of exchanging ideas with non Chinese students and expanding their perspectives .

M

\section{Teaching the ISP: Getting Off to a Bad Start}

y first experience teaching comparative education to the ISP was far from being a success. I chose the text Comparative education: Exploring issues in international 
context (Kubow \& Fossum, 2007) which presumed a much greater knowledge of recent global history than the students had. Overall, the course proved to be a frustrating experience for all concerned. Determined to do better the following year, I asked myself "what strength can I build on that these students bring to the course?" The obvious answer was that they bring a lifelong experience in the Chinese educational system, an experience I suspected they had not reflected upon.

As you have noted, Chinese education is very much exam-oriented due to its overemphasis on selecting students for advanced education. Teaching and learning have mainly focused on in-depth subject knowledge. Curriculum in post-secondary institutions carries on this tradition and focuses on courses in the students' major. There are few courses on global events, international education contexts, etc. offered to students. This accounts for the difficulties experienced by your students when faced with the particular international examples in the text-you selected. It also reinforces my earlier point that freeing themselves from the constraints of their own worldview, requires, among other things, learning about the worldviews of others.

Since this was a comparative education course, I took comfort in the fact that another course that the ISP students take involves a study of Canadian schooling and includes visits to a wide range of educational institutions in the region. I, therefore, decided to examine the Chinese educational system with the comparative aspect being education in Ontario as examined in this other course.

Good point. Although I still question the decision to treat the ISP students as a selfcontained cohort, this arrangement does provide the students with opportunities to expand their worldview which partially overcomes the disadvantage of studying in a culturally homogeneous class. These opportunities include the fact that (a) they are in a Canadian university and hearing a Western perspective from their professors; $(b)$ they are living in Canada and interacting, to some degree, with Canadians and other international students; (c) they are visiting Canadian schools and studying Canadian educational theory in other classes. As reported below, one of the students expressed her appreciation of learning critical thinking through topics on China in your class and topics on North America in other classes.

Claiming no expertise in Chinese education but with the assistance of a Chinese graduate student who was not part of the ISP cohort, I identified a series of readings that dealt with the challenges facing the Chinese educational system, most of which were written by Chinese scholars or Chinese educational officials. The intention here, in addition to finding course-appropriate literature, was to deflect possible criticisms that I was engaging in a foreign critique of China and Chinese education.

I think your deliberate choice of readings from Chinese scholars and officials definitely reduces students' sensitivity toward foreign criticism. I am curious if you also chose some articles written by Western scholars and compared students' comments on these readings? Recognizing from what perspective critiques are made, I think, is important in critical thinking. 
If teaching critical thinking skills to the ISP students was a challenge, doing so with China as the focus of inquiry added to the complexity of this task. This approach flew in the face of the advice of some of my colleagues to critically examine education in Canada, not China. It was my opinion that critiquing the Other (in this case, the Canadian education system) is hardly a test of one's critical thinking abilities because such a critique does not hit close to home. The students' ownership of critical thinking becomes pertinent when the critical lens is focused on ideas, values, institutions, and practices that are near and dear to them and which have been previously unexamined by them. While I was aware of the Chinese students' sensitivity and tried to mitigate it with my choice of readings, my strategy proved to be only partially successful.

The reflections that follow are based on seeking answers to four questions:

1. Are Chinese students in the ISP adequately prepared to undertake graduate studies in which "working at a graduate level" is generally defined as achieving the analytical competence associated with developing critical thinking skills and applying them ever more competently as they progress through their program?

2. Are Chinese students in the ISP disposed to actively embrace, as opposed to passively resist, learning critical thinking skills, particularly when the instructor takes China as the object of inquiry?

3. Did I teach transformative second wave critical thinking skills or, in effect, did my efforts constitute a mainstream, first wave interpretation of critical thinking?

4. Is teaching critical thinking using China as the object of study a legitimate scholarly pursuit designed to expand the students' academic skill set or is it, in effect, a neocolonial conceit?

The questions you raise here are highly relevant to the objective of your teaching. The last question is very thoughtful because it reminds us of the potential neocolonialism and educational hegemony resulting from globalization and students' international mobility.

As I have experienced the confusion and ambiguity caused by the concept of critical thinking, I think a fundamental question for this group of Chinese students is: What does critical thinking mean to you? This question will clarify students' learning needs and direct what and how critical thinking can be taught through the course/program.

\section{The Methodology Employed and Its Limitations}

Of the 15 students in the second iteration of this comparative education course, I was only able to interview seven. Several, corresponding to those who were least happy with the course's orientation, declined to be interviewed and others dispersed before I was able to speak to them. Despite the fact that I did not have the opportunity to interview a larger, more representative sample, I was present for some very lively, and occasionally very heated, classroom discussions as students took up the issues that were raised in class. Nonetheless, had I been able to interview even one or two of the dissident voices ${ }^{1}$, my data would have been richer. 
I sensed ethical concerns from those students who refused to participate in this study. As you say, some students were not happy with the course orientation. If they had participated in the interviews, they would have felt obliged to express their disagreements or negative feelings about the experience directly to you, the instructor. My guess is that they would have felt very uncomfortable with this for reasons I have already mentioned. If you repeat this study, it may ease students' concerns if you use a third-party interviewer, rather than conducting the interviews yourself.

\section{Critical Thinking and Graduate Students Educated in China}

If Canadian students arrive at university with limited critical thinking skills the Chinese students in the ISP cohort typically arrive, with rare exceptions, with no history of learning critical thinking. Furthermore, they come from an academic culture which employs a discourse and practice that actively discourages such inquiry.

I don't agree with point you make in this statement. As I said, critical thinking has not been an official discourse in Chinese curriculum until very recently. Students have learned some critical thinking skills, such as reasoning, logic, and inductive and deductive arguing, but they don't necessarily know that this is what is called critical thinking. Chinese students who go overseas for graduate studies are normally strong in these aspects, according to my personal encounters with students in similar situations. As for the second point, this is true in general sense, but not absolutely. Studying in schools in big cities gives students more opportunity to develop first wave critical thinking than those in rural areas.

The shortcomings of this system, based as it is on the passive transmission of knowledge, is beginning to be recognized at the highest level of the Chinese academic and political elite (Lam, 2006). But the combination of centuries-old traditions and the entrenchment of the NCEE heavily pressures Chinese teachers not to stray off paths that lead to student success in those life-altering examinations. By the time students reach university, the habits of mind that provided the academic ability to achieve acceptance into postsecondary institutions are well established, and, if the accounts of the ISP students reported below are accurate, little happens during their undergraduate years to challenge these habits.

I recognize that not everyone will agree with this assessment. Bell (2008), for example, argues that his Chinese graduate students at Beijing's Tsinghua University exhibit a well-developed capacity to critique existing practices in China although his short article does not allow him to suggest where his students learned the skills that he ascribes to them or to what extent this situation is typical. My colleague, (xxxx name of colleague), who has taught both graduate and undergraduate students in China, argues that there was a wave of critical pedagogy in China beginning in the 1980s (XXXX name of colleague, personal communication, 2008). (XXXX name of colleague) appreciation of the situation and the critical pedagogy that he used in his classes in China, stands in contrast to my experience with the Chinese students I have taught recently who repeatedly told me, as the interviews reported below indicate, that their educational experiences were characterized by receiving instruction which involved a great deal of memorizing in class and the regurgitation of information for exams. None of them 
reported engaging in processes which encouraged them to develop their own ideas, particularly when that involved challenging conventional wisdom.

There seems an apparent contradiction between these students' response and my earlier statement regarding-the evidence of first wave critical thinking being taught in China, something which both Bell and (XXXX name of colleague) agree with. Is it possible that this apparent contradiction arises because first wave critical thinking distracts from second wave critical thinking? I would interpret your students' responses as an indication of the absence of the second wave of critical thinking in their prior educational experience. You have indicated that the objective of this course is to develop the second wave critical thinking, which is legitimate because this is what Chinese students have not been formally taught before coming to Canada.

Added to this academic experience, we must consider the linguistic complication inherent in the very term critical thinking which carries a connotation of negativity both in English and Chinese. Little wonder, then, that the Chinese students, when asked to consider "critical perspectives on Chinese education" interpret this as requiring them to find fault with their country and its educational system.

I agree as I have already noted above.

\section{Attitudes of ISP Students towards Critical Thinking and the Perceived Criticisms of China}

Leaving aside the issue of whether I was, in effect, teaching first wave or second wave critical thinking - I return to this in my findings - what was the reaction of the ISP students when faced with the requirement to apply critical thinking to China and to Chinese educational practices in my comparative education course?

I asked each student who I interviewed if he or she felt comfortable with the course expectation that they apply critical thinking to the Chinese educational system. Jasmine $^{2}$ said "I appreciated the course expectations [with respect to] critical thinking. I think what Chinese students lack is critical thinking so when I saw the expectations I thought it was very useful and meaningful to Chinese students." She also said that the critical thinking skills in other classes focused on North American examples, whereas the comparative education class presented "the negative part of our Chinese educational system and society so it was more relevant for us." My interview with Jasmine was the first of the seven and I took particular note of her use of the word "negative." It would not be the only time I heard this choice of words to describe how they saw China being depicted.

Jasmine's use of the word of negative implies her understanding of critical thinking as negative thinking, which, as I have already noted, is based on the Chinese connotation of the concept critical. Even if the topics in your course were not about China, this conceptual confusion would nonetheless exist. This use of terms like "negative" and "problem" confirms the need for conceptual clarification about critical thinking. 
Critical thinking need not be negative or destructive thinking; often it is a very positive activity, producing genuine knowledge and a satisfying feeling of justified confidence in that knowledge. It is also not contrary to creative or lateral thinking. From your students' comments, I don't think they have understood critical thinking in a deep sense. This is hardly surprising since, as Paul (1994) suggests, such an understanding will not be achieved overnight.

Dawn, too, equated critical thinking with negative thinking when she said "I think your class was very useful because we learned to use critical thinking and we found some problems with our Chinese education system." She remarked that during her educational experience in China

our teachers told us the way to think about our country, that it was great, and had no problems, but now I think this course helped in that aspect. We must realize the negative (my emphasis - XXXX first author's initials) aspects so we can make changes and improve conditions to make our country better.

Her reference to the course presenting, in effect, the negative parts of "our Chinese educational system" reinforced my fears that I had failed to effectively communicate the fact that critical thinking does not simply equate with negative thinking.

Dawn's critical comment about the Chinese educational system reflects widespread criticism of educational practice within China. Regarding your fear of failing to communicate what you had hoped for with respect to critical thinking, she says she realizes now, as a result of your class, that "we can make changes and improve conditions to make our country better." To me, that represents successful critical thinking.

Louise brought a very personal perspective to the discussion. She is older than her classmates, and, as a young child, she participated in the Tiananmen demonstrations. She said that the Tiananmen events were life altering for her and that she appreciated the orientation of the course. She said

In this course we learned more about our own system. In China maybe we ignored a lot of things about our own educational system, but here we have developed very clear ideas about our Chinese system, both the advantages and disadvantages. In China, as students, we just comply and never have deep thoughts about the system and, as a result, we ignore both the good and the bad.

Joanne found the class to be "helpful" and she identified "lack of equity" with respect to access to education to be the most interesting theme. When she was in China, she did not think this was a problem but "from some of the articles, I find that lack of education equity in China is a very large problem." A number of the students researched the lack of equity in Chinese education for their exit projects.

Julie was the only student interviewed who commented on the fact that I had built the course around the framework of globalization and the neoliberalization of China. She suggested that she learned more about China from the course than about Chinese education. 
Julie's response indicates that she is able to see issues about China as part of a bigger picture and I believe this is part of what you planned to achieve from this course. However, other students' comments indicate their worldviews are still dominated by the socialization and life experience with which they are most familiar. They are not empowered yet to think critically in a strong and broad sense, considering their short stay in Canada at the time of taking this course.

Eliza said the most memorable aspects of her experience in the program were the class presentations and writing essays. These activities "pushed our thinking to write things we never thought about before." Doing the class presentations, "put us in the position of teaching ourselves and teaching our classmates, not just us sitting there to receive the knowledge from the teachers like in typical Chinese classrooms."

All of the students interviewed said that the course, in the words of Jasmine, gave the students the opportunity "to see what's happening in China." Jasmine added that it was important "that the Chinese students ... see the things that they view as negative because the Chinese system exposes us too much to the good parts and omits the socalled bad parts."

Your findings here resonate with the findings of my research. Due to the narrowness of the undergraduate curriculum, Chinese students are not oriented in their studies to see the bigger picture. There is an urgent need to update or reform the undergraduate curriculum in Chinese post-secondary institutions.

Dawn noted that "in China we didn't get such access to know the problems that exist in the Chinese educational system and you offered us a balanced attitude and [an opportunity to] develop some thoughts on what changes might improve the Chinese educational system."

Lance, in his response to my question about the extracts from the two documentaries we saw, said "I am patriotic. I love my country, so you can tell me the truth [about it]." Referring to some segments of a Public Broadcasting System (2006) documentary on China, Lance said

Young people in China would like to see such films but they don't have the opportunity. If you visit the PBS home site in China they will block it. If you post anything that criticizes the Communist Party ... your entry will be deleted. So, I really enjoy the freedom here. It's very important. Ironically, despite the fact that many of the students mentioned that Chinese young people do not have access to the type of information or analysis that we dealt with in class, when asked why they felt comfortable engaging in what was perceived as a critique of China when some of their peers did not, a number of the students (e.g., Jasmine, Julie, and Dawn) defined themselves, in effect, as "inside dopesters" replying essentially that unlike their fellow students, they already knew that the situation was different than the official version. They attribute this to having parents who work as relatively senior officials within the state apparatus. 
Interesting. Media in China are perceived as the "tongue" of government by both government and citizens. Many people read media reports and articles, but form their opinions based on internal news sources (the unpublicized reality). It is ironic that the distrust of public media is evident and pervasive in China and citizens have learned to cope with the displacements of living in two worlds.

\section{The Documentary Film:}

I showed an extract of one film, Manufactured Landscapes, documenting Burtynsky's photographic expedition to China (Baichwal, 2007). Manufactured Landscapes depicts diverse aspects of Chinese economic life including scenes of the working conditions in factories and environmental issues related to the impact of the Three Gorges Dam and the degradation caused in one community, particularly to its water supply, resulting from disassembling old TVs and computers sent from the West to be recycled.

The scenes in Manufactured Landscapes that depicted the environmental impact of China's growth elicited a strong response. Some were moved by the extent of environmental degradation depicted in the film (Dawn, Julie, Eliza, and Lance) while others (and this was expressed in class discussion principally by those who declined to be interviewed) were upset that foreign film-makers were documenting such scenes and embarrassing China. While most of the students debated the appropriateness of showing such scenes, only one student picked up on the message that China and the West share responsibility for the impact of China's role in the international division of labour. The products depicted in the film, both those that were being assembled and those that were being disassembled, were made under contract to supply Western markets.

Louise, perhaps, best captured the ambivalence that the students felt towards Manufactured Landscape. She confessed to being "a little bit ashamed about the Chinese current situation," stating that "these things" happen but when she talks to Westerners, she says, "I don't want to know how bad things are from others." Louise suggested that some of the younger students took criticisms of China personally as they would if someone criticized their parents. She said their attitude was "I can make these criticisms but you can't."

You were teaching this class in the January-March period preceding the August, 2008 Olympic Games. It is important to remember that during this pre-Olympic period, the Western media were full of frequently negative stories about China. This could easily have contributed to a particular sensitivity on the part of your students but Louise is right to point out that, at the best of times, we Chinese don't like hearing criticisms of China from Westerners, even if we might make those same criticisms ourselves.

In response to a question about whether the experiences that she and her classmates had in this course had created a positive energy or divided the class, Eliza, echoing Paul's (1994) observation that criticality takes years to achieve, said that the negative reaction by some was "natural" because "this is our first year in the country and most of our classmates never went abroad before." She continued 
When we suddenly faced all that information that criticized the phenomena of China, the first reaction will be to resist. Although inside our hearts yeah, that's true, but the first reaction will be to resist. If we ... stayed in Canada, for example, for more than one year [and became] familiar with the international environment, we [would get] more absorbed and [learn] to face those issues, [whereas] back in China all the media surrounding us always praises things in China.

Eliza's comment reflects my previous observation about the Chinese media. Her response is quite critical, isn't it? She can relate her experience with the reality and her situation and is able to vision the future changes. Her comments provide evidence of the achievement of learning objectives.

\section{Findings}

\section{(i) Do the Chinese students arrive prepared for work at a graduate level that involves critical thinking?}

I have argued that the Chinese educational system is characterized by its reliance on the passive transmission of knowledge and that this is reflected in the years of preparation for the NCEE. The habits of mind developed as a result of this approach to teaching and learning do not prepare the students for critical thinking.

I acknowledge the objection to this characterization of Chinese education but I maintain, in the face of my classroom experience teaching in the ISP and the repeated assertions to this effect by our visiting Chinese students who, after all, recently graduated from a large number of Chinese universities, that this characterization is accurate whatever exceptions to the rule may exist. Given this observation, the next question becomes key.

You will anticipate my response to this based on my earlier comments. I think it would be more accurate to say that Chinese students are not prepared for critical thinking as defined in terms of the critical pedagogy tradition developed from Freire (1970), Shor (1992), and Giroux (1994), who address issues of power and social justice.

Increasingly, Chinese students are learning the critical thinking skills associated with what you refer to as first wave critical thinking associated with Ennis (1996) and Siegel (1997), whose approach stresses rational and logical reasoning above all. In practice, the impact of this approach is uneven as classroom teachers struggle with implementing what are, for them, new and difficult concepts. 
(ii) Are the Chinese students in the ISP disposed to embrace, as opposed to resist, learning critical thinking skills particularly when the instructor takes China as the object of inquiry?

The group seemed evenly divided between those who, for the most part, approved of-and those who were, to one degree or another, unhappy with my efforts. It is difficult to accurately document dissenting sentiments because the very students who were most uncomfortable with my approach declined to be interviewed. Given the number of students who, in the interviews, referred to how I had them look at the "negative" aspects of China, it is perhaps not surprising that some of their classmates believed that China was being subjected to something that was not balanced or fair. Nonetheless, a lot of the students, even if they chose the word negative to describe the readings on Chinese educational issues, appreciated the opportunity to reflect on the problem areas identified in the literature. In short, a group of students, who were more or less homogeneous, split with respect to their reaction to the class materials and discussion.

The greatest resistance occurred the day I showed excerpts from Manufactured Landscapes. This film clearly touched a nerve with most of the students. The greatest consensus occurred the day we discussed the article National college entrance examinations: The dynamics of political centralism in China's elite education (Feng, 1999).

The classroom discussion on the NCEE examined the phenomenon of these nation-wide standardized tests and was, at times, quite emotional. While none of the students could propose an alternative as to how to apportion China's limited postsecondary spots to the millions of students who vie for them each year, they all agreed that the NCEE and the preparations for it constituted a deeply stressful experience for them.

I can only conclude that, when teaching about China from a critical perspective to Chinese students, to avoid a reaction that shuts down communication and critical reflection, the instructor is well advised, at least initially, to find a topic that the students themselves understand to be problematic. The NCEE is certainly one such topic;; environmental degradation is not, at least as depicted in Manufactured Landscapes.

I agree with you here. However, you must remember that the importance attached to critical social issues differs from country to country. Environmental degradation has not been prioritized or recognized by Chinese government as being as serious as other social issues (e.g., poverty in rural areas, high rates of unemployment, social instability, and so forth). In fact, the environmental degradation depicted in the film can be seen as resulting from the economic strategies aimed at alleviating these serious socio-economic issues. The film Manufactured Landscapes, for example, ignores the background reality that the workers shown doing the work that is so environmentally destructive are drawn from conditions of extreme poverty and the work they are doing constitutes their escape from that impoverishment. Through globalization, these jobs have been shifted to lowwage China so that the Western world can have access to low-cost merchandise. Environmental degradation is a very serious problem considered globally, but not locally. I am glad that one of the students pointed out the connection between Chinese environmental issues and Western consumerism. If this connection is not made, no 
critical learning can occur on this topic. Frankly, the concern about environmental degradation in China has been an ache in my heart for many years.

(iii) Did I teach transformative second wave critical thinking skills or, in effect, did my efforts constitute a first wave interpretation of critical thinking?

Despite my advocacy of critical pedagogy as developed by Freire and his successors in my writings (XXXX first author's refernces), I can produce no evidence that, as a result of this course, any of the students began to construct a worldview that significantly broke with the one they had been socialized in. It is true that

- Lance critiqued the lack of freedom in China as manifested in the inability of young people to access certain websites (he cited PBS) or to post criticism of the Communist Party without it being promptly removed;

- Julie (alone among the students) commented on the fact that I had built the course around the framework of globalization and the neoliberalization of China;

- Eliza said that the program "pushed our thinking to write things we never thought about before;" and

- Dawn said "we must realize the negative aspects [of China] so we can make changes and improve conditions to make our country better."

All of these statements constitute student critical thinking within the first wave tradition. This said, however, I cannot ignore the comments of Louise who underwent a significant change during the course, the depth of which I failed to appreciate until the last class. As we went around the table in a summative exercise, she told us that, until this course, she had given up on China. She said:

When I came to Canada, I was determined to try to stay here because I had given up on my country but Michael taught me that changes are possible in my country and I want to go back there and contribute to that.

While I was moved by the excessive credit she gave me for her change of heart, it made me realize the potential inherent in the opportunity that a foreign educational experience offers her and her peers to stand back from their lived experience and reflect on options they had not previously considered.

Her comment, and those of her classmates who welcomed my efforts, helped answer my doubts about whether my apparent inability to move these students beyond the first wave paradigm constituted a pedagogical failure on my part or constituted a step towards developing their thinking autonomy? Despite the arguments of Walters (1994) and others, that first and second wave critical thinking constitute two distinct, and mutually exclusive, paradigms, I came to the conclusion that the Chinese students in the ISP who began to question certain important aspects of the worldview in which they had been socialized are opening themselves to the possibility of increasingly profound critical thinking. During a short program, such as the one that Brock offers, we can, of course, only begin to teach critical thinking skills and, I would argue, we need to make every effort to ensure that the critical thinking skills we teach correspond to those associated with second wave thinking. However, as Paul (1994) suggests, 14 months is not enough time to achieve critical thinking "in the deep sense" (p. 182). Eliza recognized this. She argued that if she and her fellow students stayed in Canada for another year and became more comfortable with the environment, they would be more likely to face the question 
of China more critically. Indeed, some of these students will be in Canada for another year or more as some move on to $\mathrm{PhD}$ programs, professional diploma courses, or seek employment to gain Canadian work experience before going back to China. To what extent these students will continue to develop their critical thinking skills will be very much an individual journey that is difficult to document.

I really appreciate your recognition of the importance of teaching critical thinking to Chinese students. In this era of globally connected world, all citizens need to take a critical view of how we are influencing, and being influenced by, each other. China is going through a dramatic transition and as global citizens we all have the social responsibility to promote social justice and reduce inequity and poverty locally and globally. Without critical perspectives and capacities, it is not possible to achieve this goal. Furthermore, I see myself in your students, and maybe some of them will have very similar experiences to mine in Canada: completing M.Ed and Ph.D programs, working in different cultural and educational contexts, being situated in a "third space" between cultures and systems. If my response to your reflections can be said to include critical thinking then that represents a hope that you will see a growth of such critical thinking skills among these students in the future.

\section{(iv) Is teaching critical thinking using China as the object of study a legitimate scholarly pursuit designed to expand the students' academic skill set or is it, in effect, a neocolonial conceit?}

I am convinced that it is both legitimate and essential to teach critical thinking to the Chinese international students because not to teach from a critical perspective means, in effect, teaching from the perspective of the dominant ideology of our society. Such an approach implicitly suggests that this is the model that China should be following. That, rather than the teaching of critical thinking, smacks of colonialism. Of course, how this critical thinking is taught is key. If a particular school of critical thinking is imposed on the students or if finding fault with China becomes the central exercise (or finding fault with Canada, for that matter), then critical thinking can be seen as colonizing the students' minds through the imposition of an "alternative package of ideas."

In my opinion, learning about first wave or second wave critical thinking is not so important as understanding the philosophical roots and pedagogic orientations of critical thinking. For me, and maybe for your Chinese students as well, learning about critical thinking constitutes learning about one aspect of Euro-western philosophical and educational traditions. This is a part of the goal and benefits of studying overseas. It also gives me the opportunity to share Chinese education, traditions, cultures, and values with you. It is a mutual learning journey, isn't it?

\section{Final Reflections}

My (O'Sullivan's) initial intention in writing this piece was simply to clarify my own thinking about the experience I had just had with the ISP students and to spark a discussion within my own faculty about the challenges facing us as instructors in this 
particular program. It never occurred to me when I sent a copy of my reflections to Linyuan, that it would result in such an informative dialogue and cause me to embarque upon such a serious, and ongoing, learning curve.

Linyuan gets to the heart of the issue in her comment about Canadian society favouring the "individual perspective and independent thinking" while, in contrast, the Chinese favour a "holistic perspective" and what she calls "the collective good" which places a great emphasis on harmony, 'not losing face', and avoiding open disagreements with others. Her initial reaction to reading my paper was to tell me that I had ignored the concept of harmony and that I couldn't possibly understand the reaction of the Chinese students to my efforts to teach from a critical perspective without coming to terms with that concept. In a subsequent communication, she wrote the following comment about critical thinking and the Chinese mode of thinking:

This dialogue on teaching critical thinking to Chinese students stimulates my thoughts on the fundamental cultural difference underlying teaching and learning in the specific field of comparative education and, more generally, in international education, both of; which must deal with issues in various cultural, educational, and philosophical contexts. I would argue that as educators we not only need pedagogic tact in developing curriculum and teaching methods, but we also need pedagogic sensitivity to the diverse cultural and philosophical contexts from which-students are drawn. Only by being able to understand students' cultural belief systems and the cognitive orientations developed in their prior learning, can we meet their diverse needs.

Critical thinking is not only a skill set; it also reflects the belief system and cognitive orientation of the thinker. Critical thinking-is rooted in ancient Greek philosophy and underlies the process and theory Euro-western philosophers rely on to reason, and judge the soundness of, an argument or theory (Thayer-Bacon, 2000). However, Greek philosophy, which is the foundation of Western tradition and culture, is very different from Chinese philosophical tradition, which is the origin of East Asian tradition (Nisbett, 2003).

Westerners value independent thought and the ability to debate and argue as social organizers. This belief system is not found-in Chinese culture and philosophy where harmony is valued as the central concept of Confucian-tradition. Harmony implies that the individual is primarily a component of a collective and the unity of this collective is the most important concern. Consequently, argument and debate are viewed as less acceptable social behaviors as they reduce the unity and harmony of the collective. This cultural difference explains why Chinese students are sensitive to critiques of China and why deep, or second wave, critical thinking has not been considered an important learning objective in Chinese education.

The complexity and difficulty of teaching critical thinking to Chinese students is heightened by the fact that it requires students to engage in nothing less than identity and cultural transformation. Chinese students who are suddenly faced with the requirement 
to "think critically" must come to terms with their ambivalence towards this-concept. This-constitutes both an intellectual and a cultural challenge requiring time, practice and disposition. The most important of these is-disposition. They are being challenged by their professors to operate within the framework of a totally foreign philosophical orientation - a requirement that most of their professors have never had to face themselves.

The statement that learning critical pedagogy requires Chinese students to engage in cultural transformation needs to be explored deeply. If this is the case, it is hard to escape the conclusion that instruction is, indeed, neocolonial. Linyuan, however, doesn't come to that conclusion. Students in China, she notes, are being taught first wave critical thinking, that is, the development of reasoning skills. What they are not taught, she contends, is second wave critical thinking skills of the sort associated with the critical pedagogy movement. Despite her observations about transformation inherent in such instruction, she suggests that it is a legitimate educational goal to engage in such instruction "because this is what Chinese students have not been formally taught but hopefully, through the critical lens, Chinese students become more aware of and sensitive to neocolonialism in education."

The challenge then is how to teach critical thinking to the Chinese students that goes beyond first wave critical thinking, and promotes the ability to reflect on the ideological forces that shape our worldview, and develop that "autonomous thinking" and "critical empowerment" to which Paul refers, while respecting the fact that Chinese students have been educated in an intellectual tradition that prizes harmony and deplores conflict, including the conflict inherent in intellectual contention. How to best achieve this requires ongoing research and reflection by those of us engaged in teaching critical thinking to Chinese students or, for that matter, to any student who comes to us from an intellectual tradition different than our own.

My engagement with Linyuan on these issues has led me to explore Western and Asian modes of thought (Nisbitt, 2003) including the issue of harmony and conflict in those two traditions, and how these modes of thought manifest themselves in the classroom, particularly our internationalized classrooms where so many of our students were raised in cultures different than that of the instructor. It has led me to consider how to approach critical thinking in the framework of the ISP and, while I remain convinced that teaching critical thinking, including second wave critical thinking (or critical pedagogy) remains a valid exercise to engage in with these students, I do so with less certainty and more open mindedness than I did during the class discussed in this paper. Ironically, this process has caused me to appreciate more fully the challenges involved in teaching critical thinking to Canadian-born students. Our popular culture is decidedly non-critical and anti-intellectual and to promote criticality in our students requires pedagogical strategies that go far beyond merely asserting the importance of being critical and insisting, as Linyuan's professors did, that she approach the topic under consideration "more critically". The dialogue with Linyuan has resulted in my revisiting the literature on critical thinking and critical pedagogy and reconsidering my practice both in the ISP classroom and in my "regular" classrooms as well. 


\section{Endnotes}

${ }^{1}$ My choice of the word dissident to describe these students who expressed discontent with some or many aspects of what I was attempting to achieve during the course is not meant to be disparaging. They were, after all, dissenting and doing so consistently but in a way that provoked dialogue in the class. Their dissidence constituted an important element of the class dynamic and led to this reflective piece.

${ }^{2}$ I have substituted "English pseudonyms" for the students' "English names." 


\section{References}

Baichwal, J. (Director). (2007). Manufactured landscapes [Motion picture]. Canada: Foundry Films.

Bell, D. (2008, August). Chinese students' constructive nationalism. The Chronicle Review, B20.

Feng, Y. (1999). National college entrance examinations: The dynamics of political centralism in China's elite education. Journal of Education, 181(1), 39-57.

Freire, P. (1970). Pedagogy of the oppressed. New York: Seabury.

Giroux, H. (1994). Toward a pedagogy of critical thinking. In K. Walters (Ed.) Rethinking reason: New perspectives in critical thinking (pp. 199-204). Albany, NY: State University of New York Press.

Ibrahim, T. (2005). Global citizenship education: Mainstreaming the curriculum? Cambridge Journal of Education, 35(2), 177-194.

Kubow, P., \& Fossum, P. (2007). Comparative education: Exploring issues in International Context. Upper Saddle River, NJ: Pearson Education.

Lam, W. (2006). Perpetual challenges to Chinas' education reform. China Brief, 6(24). Retrieved April 4, 2007 from www.jamestown.org/publications.

Nisbitt, R. (2003). The geography of thought: How Asians and Westerners think differently ... and why. New York, NY: The Free Press

XXXX two references by the first author ....

Paul, R. (1994). Teaching critical thinking in the strong sense: A focus on self-deception, world views, and a dialectical mode of analysis. In K. Walters (Ed.). Re-thinking reason: New perspectives in critical thinking (pp 181 - 198). Albany, NY: State University of New York Press.

Public Broadcasting System. (2006). China from the inside [Motion picture]. United States: PBS.

Shor, I. (1992). Empowering education: Critical teaching for social change. Chicago: University of Chicago Press.

Thayer-Bacon, B. (2000). Transforming critical thinking: Thinking constructively. New York: Teachers College Press.

Walters, K. (1994). Introduction: Beyond logicism in critical thinking. In K. Walters (Ed.) Re-thinking reason: New perspectives in critical thinking (pp. 1-22). Albany, NY: State University of New York Press.

Assigned Readings in EDUC 5P70 Comparative Education

Chan, D. (2007). Global agenda, local responses: changing education governance in Hong Kong's higher education. Globalization, societies and education, 5(1), 109124.

Dongping, Y. (2007). Pursuing harmony and fairness in education. Chinese education and society, 39(6), 33-44.

Feng, Y. (1999). National college entrance examinations: The dynamics of political centralism in China's elite education. Journal of education, 181(1), 39-57.

Guan, X. (2000). China's social policy: Reform and development in the context of marketization and globalization. Social policy and administration, 34(1), 115130. 
Jacob, W. (2006). Social justice in Chinese higher education: Regional issues of equity and access. Review of education, 52, 149-169.

Jinming, X., Jin, Y., \& Yan, Y. (2005). The future reform and development of higher education teacher training in China. Chinese education and society, 38(6), 17-38.

Lam, W. (2006). Perpetual challenges to China's education reform. China Brief, 6(24). Retrieved April 4, 2007 from www.jamestown.org/publications.

Yan, L. (2007). The socialist state and global capital: Educational retrenchment and crisis in China. Chinese education and society, 40(1), 9-21. 